\title{
A LOGÍSTICA DA HIDROVIA DO MADEIRA NA EXPANSÃO DA SOJA NA AMAZÔNIA
}

\author{
Carlos Alberto Franco Da Silva' \\ Universidade Federal Fluminense
}

A partir da década de 90 do século XX, parcelas do território da Amazônia, sobretudo áreas do cerrado, foram incorporadas ao processo de avanço da fronteira agrícola capitalista capitaneada pela lavoura da soja. As áreas inseridas neste processo são os cerrados e campos de Mato Grosso, Rondônia, Amazonas, Pará, Tocantins e Roraima. Alguns agentes são representativos da dinâmica de transformação dessas porções territoriais. Dentre os atores que constituem parte integrante de práticas constitutivas de novos arranjos territoriais, sob a égide da lavoura da soja, destacam-se Estado, pequenos e grandes produtores e grupos empresariais, tais como CARGILL, ADM, BUNGE Y BORN, DREYFUS e ANDRE MAGGI. As práticas socioespaciais promovidas por tais atores desterritorializam grupos sociais e geram impactos socioambientais diversos. De um lado, tais problemas são decorrentes do desmatamento, perda da biodiversidade, desestruturação produtiva e cultural de grupos sociais ribeirinhos, indígenas e quilombolas. De outro, o avanço da urbanização desordenada, a modernização tecnológica da agricultura, o desenvolvimento econômico de municípios e a industrialização à montante e à jusante da agricultura difundem práticas de marginalização, exclusão e inserção precária de grupos sociais.

A fim de revelar impactos singulares no bojo de processos gerais do avanço da fronteira agrícola brasileira, este artigo se volta para a análise da privatização da hidrovia do Madeira, pois tal rede de fluxos desvela uma malha territorial, cujo controle técnico e político se afirma pelo domínio do Grupo André Maggi sobre parcelas significativas das etapas de comercializações de grãos na Amazônia, sobretudo na

\footnotetext{
${ }^{1} \mathrm{O}$ presente trabalho apresenta uma síntese das idéias centrais do livro "Grupo André Maggi: corporação e rede em áreas de fronteira”. Cuiabá: Entrelinhas, 2003, de minha autoria.
} 
Chapada dos Parecis. No entanto, antes de iniciarmos o estudo sobre a hidrovia do Madeira, cabe destacar práticas recorrentes da corporação sobre sua área de influência.

\section{O (des)ordenamento territorial do Grupo André Maggi}

O Grupo André Maggi é uma das maiores corporações agroempresariais do país. A área de atuação se estende, principalmente, pelos Estados do Mato Grosso, Pará, Rondônia, Amazonas, Paraná e Roraima. Além de atuar nas esferas de produção de grãos, beneficiamento da soja, transporte, pesquisa, energia elétrica e armazenamento, o Grupo André Maggi concentra suas práticas no processo de comercialização de grãos de soja e milho, respectivamente. Para tanto, a corporação mudou sua razão social para Amaggi Exportação e Importação Ltda. Se as articulações produtivas, mercantis e financeiras são importantes, as alianças políticas são estratégicas para a reprodução de capital do grupo. Assim sendo, a presença de Blairo Maggi, ex-presidente do grupo, como governador de Mato Grosso, revela a indissociabilidade entre a dimensão política e a econômica nas práticas de ordenamento territorial do Grupo André Maggi.

Em linhas gerais, o ordenamento territorial das interações sociais promovidas pelo Grupo André Maggi, no âmbito da expansão da soja, em áreas sob o domínio prévio do cerrado, inicia-se pela substituição das estruturas produtivas preexistentes, de modo a promover a constituição de um espaço adrede, cujo sistema de ações e de objetos é marcado pela intensa incorporação da técnica e da tecnologia, ou seja, por um processo de territorialização do capital estruturado pelos impactos da revolução técnico-científicoinformacional.

A presença de um sistema de objetos técnico-científico-informacionais é ilustrada na produção de pequenas usinas hidrelétricas, hidrovia, cidade, fazendas, indústrias de beneficiamento, controle de rodovias, centro de pesquisa, redes telemáticas, armazéns e abertura de filiais e rede de produtores. O ordenamento territorial do Grupo André Maggi é marcado por um conteúdo técnico que atende aos requisitos da inserção da corporação nos circuitos globais de capital, informação e mercadorias. Desse modo, o sistema de objetos não é apenas técnico, mas também social, ou seja, é reflexo e condição de ações políticas que participam da produção de uma ordem territorial dinâmica e funcional que se transforma em função dos padrões de produção e regulação capitalista.

Essa territorialização do capital é também expressa no controle financeiro de grandes e médios proprietários e da mão-de-obra preexistente ou trazida do sul do país. Cabe ainda acrescentar a participação de Blairo Maggi nas articulações políticas em níveis do Governo dos Estados de Mato Grosso, Amazonas, Rondônia e Pará e de diversas municipalidades, bem como suas interações estratégicas com empresas nacionais e tradings transnacionais e partidos políticos.

Tal processo de abertura da fronteira agrícola gera alguns conflitos, já que implica 
impactos ambientais, concentração fundiária, sujeição dos produtores aos esquemas de financiamento à produção, em face do novo padrão produtivo que se instala. Além disso, no encontro de culturas diferentes, os valores culturais etnocêntricos trazidos pelos grandes proprietários sulistas, a partir da ideologia da modernização, se contrapõem aos das estruturas sócio-culturais preexistentes na região.

No encontro de tempos distintos, como por exemplo, o avanço da soja em áreas próximas às comunidades indígenas, a temporalidade das ações impostas pelo Grupo André Maggi tenta inserir modos de vida tradicionais a sua órbita, tal como em Sapezal. Mas as territorialidades impactadas reagem às ações e objetos novos que caracterizam a atuação da corporação através do apoio dos movimentos de ambientalistas.

Se todo ordenamento territorial não parece um sistema fechado infenso à dinâmica geral do capitalismo nacional e internacional, o complexo territorial em rede (re)produzido pelo Grupo André Maggi é marcado pelas redes de transporte, comunicações e energia que interligam a rede urbana regional da corporação à rede urbana nacional e global. Daí a importância logística de se abrir novos corredores de exportação através de rodovias, ferrovias e hidrovias, sob a iniciativa do capital privado em parceria com o Estado.

Além da integração física do território à economia nacional, sob a égide da globalização, é fundamental a sua inserção no espaço de fluxos imateriais de circulação de capitais e informações em escala global. Assim sendo, o Grupo investe em redes comunicacionais informatizadas através de acesso a satélites de transmissão, compra de equipamento de comunicação, telefonia celular etc.

A presença de um sistema de objetos pontuais ou em manchas (áreas de produção) disperso ou concentrado em vários lugares e regiões do país revela a dinâmica de inserção de territórios e espaços nacionais à órbita dos interesses do grupo, em face de sua força política e da capacidade de acionar os vetores de modernização dos padrões técnico-produtivos do território brasileiro. Assim sendo, as práticas sociais do Grupo André Maggi expressam uma tendência de corporatização do território em áreas de fronteira agrícola em expansão ou consolidadas, visto que outras tradings, tais como CARGILL, ADM, BUNGE Y BORN e DREYFUS, atuam e dominam a comercialização de grãos no país.

A maior complexidade entre as formas que compõem o ordenamento territorial das relações entre as operações de produção, processamento, distribuição, armazenamento e comercialização tem enfatizado o papel do controle da informação como elo central de um espaço agrário técnico-científico-informacional. Esse fenômeno é parte integrante do advento da sociedade em rede e da revolução dos serviços. O padrão moderno de ordenamento territorial do complexo da soja está intimamente ligado à capacidade de controlar e administrar fluxos de informações mediante sistemas de rede de comunicações e de transporte, de modo a permitir uma eficiente integração entre os diversos tipos de capitais envolvidos na dinâmica do complexo territorial agro-urbano-industrial. 
O controle das redes de fluxos visa a regular os processos produtivos e a circulação de resultados, evidenciando a normatização do território da corporação. As normas, entretanto, não se limitam apenas ao processo contábil, mas, ante de tudo, revelam o comportamento político e as interações da corporação com o poder público e outras empresas, que podem ou não ser concorrentes. Ou seja, como afirma SANTOS (1996, p.183), "as normas de ordem técnica são também políticas". Para tanto, o controle e incorporação da informação nos objetos que formam o recorte espacial do grupo é o fator fundamental para o processo social de competitividade intercapitalista.

Desse modo, tem-se um processo de informatização do território, já que o ordenamento territorial é profundamente marcado pelas transformações na composição técnica, em face dos investimentos em infra-estrutura, e por uma composição orgânica do território constituída pelas biotecnologias, inovações químicas, informática e eletrônica. Tais elementos são fundamentais para a instrumentalização do território.

No que diz respeito à produção, o ordenamento territorial é acompanhado por um ordenamento ambiental que dê funcionalidade à escala de produção desejada. Desse modo, um intenso processo de transformação do ecossistema local se faz necessário. Embora haja resistência de grupos marginalizados e de ambientalistas, à medida que 0 desmatamento avança, a natureza é refuncionalizada, de modo a se adequar aos ditames da revolução técnico-científico-informacional. Mesmo que haja no cerrado condições favoráveis, como topografia, temperatura, distribuição de chuvas e luminosidade, o solo necessita ser corrigido. O domínio sobre a natureza se dá através da adubação, irrigação, uso de máquinas etc. Apesar dos recursos mecânicos, informatizados e de telecomunicações, a fim de se implantar uma tecnologia de processos produtivos compatível com a nova geografia da produção, os impactos da biorrevolução constituem o elemento-chave para o ordenamento territorial que ali se realiza. O uso de sementes melhoradas e adequadas à diversidade regional é o primeiro passo da verticalização da produção. Assim sendo, justifica-se a presença de um centro de pesquisas biotecnológicas, a Fundação Mato Grosso, que funciona em convênio com empresas privadas.

A articulação entre inovações mecânicas, físico-químicas e biológicas visa a aumentar a produtividade do trabalho, superar as barreiras naturais e aumentar a velocidade de rotação do capital. De fato, a aplicação de tecnologias na produção agrícola provoca uma fluidez do espaço disponível ao cultivo de grãos de soja.

De um modo geral, o ordenamento territorial e ambiental promovido pelo Grupo André Maggi em áreas de domínio prévio do cerrado do Centro-Oeste e nos campos abertos da Amazônia, é parte integrante das transformações do modelo de acumulação de capital e das políticas neoliberais que o acompanham. A nova organização espacial da produção é assentada numa busca de controle da iniciativa privada sobre a infraestrutura de transporte, urbana e de telecomunicações. O papel do Estado se resume às parcerias na divisão dos custos dos projetos e à normatização e controle, no âmbito da concorrência. 
Assim sendo, tais práticas engendram um integrado sistema de relações sociais. Logo, o ordenamento territorial do grupo é marcado pelas redes telemáticas, de transporte e de gestão. As redes (re)produzidas pelo Grupo André Maggi constituem o elemento básico da ordem implícita na organização socioespacial da expansão da fronteira agrícola da soja e nascem a partir de determinações ou imposições (regras, especializações, ajustamentos etc). A materialidade dessa rede territorial, ou desse território em rede, fixa as possibilidades de interações entre diversos atores e lugares que compõem a rede e constitui uma das bases do ordenamento territorial.

Apesar de o Grupo André Maggi ser um dos atores hegemônicos na produção e comércio de grãos de soja no Brasil, a gestão maior do circuito mercantil-financeiro está em poder de atores transnacionais. Desse modo, a dinâmica espacial do grupo é apenas parte integrante das verticalidades globais do agronegócio da soja.

Assim sendo, o cerrado e os campos da Amazônia se apresentam com imensas possibilidades de apropriação de porções do espaço, em face da extensão territorial da fronteira agrícola e das estratégias políticas das corporações e latifundiários. Configuram-se como um espaço onde é possível implantar novas estruturas produtivas, eixos de transporte para importação e exportação de mercadorias, bem como inserir localidades no mercado financeiro mundial. Desse modo, estratégias espaciais emergem, a fim de alcançar a escala condizente com a mobilização de recursos prevista. Nesse sentido, a gestão territorial se associa à lógica da empresa.

De acordo com Becker (1988:3), "a gestão é a prática estratégica, científicotecnológica do poder no espaço, que dirige no tempo, a coerência de múltiplas decisões e ações para atingir uma finalidade". É no bojo dessas ações estratégias que se insere a logística. A análise da logística das redes do Grupo André Maggi envolve vários elementos fundamentais: os eixos de transporte para exportação da produção de soja; importação de insumos (adubos e fertilizantes); criação do núcleo urbano de Sapezal (MT), produção de energia elétrica, implantação de armazéns em locais estratégicos, controle do tráfego de caminhões, criação de centros de pesquisas (Fundação Mato Grosso) e parcerias políticas e empresariais.

Dentre os mais importantes elementos de integração e ordenação de um território que já assume feições transnacionais, destaca-se a hidrovia Madeira-Amazonas, projetada pela Empresa Hermasa, que pertence ao Grupo André Maggi. Assim sendo, a análise da gênese da Hidrovia Madeira torna-se reveladora das estratégias de reprodução ampliada do capital e da escala espacial de atuação do grupo.

\section{A gênese do processo de privatização da hidrovia do Madeira}

Em 1986, André Maggi, pai de Blairo Maggi e ex-presidente do grupo, decidiu expandir seus negócios em Mato Grosso. Acompanhando as áreas de domínio de cerrado, passou a pesquisar a região noroeste do estado, na Chapada dos Parecis, no então município de Diamantino. As terras de excelente qualidade e de baixos preços, 
em razão da distância aos grandes centros urbanos e da falta de infra-estrutura, foram fatores que levaram André Maggi à prática da antecipação espacial. Para tanto, adquiriu 12 mil hectares, mais tarde ampliado para 70 mil hectares, dando origem a Fazenda Tucanaré, às margens do rio Sapezal.

A fazenda possuía uma antiga sede e estava voltada para a lavoura de arroz. De início, André Maggi e Blairo Maggi ficaram dois anos sem investir na propriedade. Nas visitas que faziam à fazenda, planejavam construir uma cidade, plantar 20.000 hectares de soja, produzir sementes, instalar uma usina hidrelétrica e no futuro transportar a soja pelo rio Madeira, alterando a logística de transporte dominada pelos portos do sul do país.

Nesse momento, não havia um projeto de porto, apenas a idéia. De acordo com Blairo, "era um sonho meio solto, que você geograficamente olhava e observava que a soja tinha que sair para o norte, não tinha jeito" (Entrevista realizada em $11 / 06 / 01)$.

O projeto da hidrovia só começou a surgir quando em julho de 1989 , um produtor da região de Sapezal, chamado Gentil Grapeja, soube que haveria um seminário sobre a possibilidade de implantação da Hidrovia Madeira-Amazonas, organizado pela Portobrás, em Porto Velho. Ao se informado pelo Gentil, Blairo Maggi ligou para seu superintendente Jacyr e foram os dois para Porto Velho participar da reunião.

Neste seminário, Blairo percebeu que o projeto da hidrovia requeria um tripé formado pelo produtor, exportador e proprietário dos armazéns. Para que esse tripé garantisse a fluidez da produção e sua comercialização era importante investir nas rodovias de acesso ao porto, em Porto Velho (RO). Entretanto, para a sustentação do projeto, todos os participantes apontavam para a garantia de que haveria ou não soja para transportar.

Após o seminário, a discussão do projeto da hidrovia foi esquecida. Não havia uma produção de soja na Chapada dos Parecis que viabilizasse a implantação da hidrovia Madeira-Amazonas. De qualquer maneira, estavam presentes na reunião pessoas de grande influência política e econômica: um armador de São Paulo, membros do Ministério dos Transportes e um representante da Portobrás, Nélio Rocha.

Uma semana após esse encontro, Nélio Rocha convidou Blairo Maggi para visitálo em Brasília para uma conversa sobre a hidrovia. Nesta reunião, Blairo foi apresentado ao Sr. Hernandes, da Hernavi Marítima de São Paulo. Assim, surgiu um grupo de trabalho. Blairo, um grande produtor e comercializador de soja, e Hernandes, ligado ao setor de transporte, iniciaram um estudo sobre a viabilidade técnica e econômica da hidrovia.

A discussão técnica e política era o primeiro obstáculo. No seminário de Porto Velho, os representantes do Pará defendiam a saída da soja pelo porto de Santarém e o grupo do Amazonas sugeria a saída por Porto Velho. Os políticos do Amazonas saíram na frente em defesa de Itacoatiara.

O grupo de trabalho formado pela Hernavi e Grupo André Maggi criou a Empresa 
Hermasa S/A e iniciou as pesquisas técnicas. A distância das áreas de produção de soja de Mato Grosso dos centros exportadores do sul do país criava uma necessidade vital para o processo de reprodução ampliada do capital: a instalação de um novo corredor de exportação que viabilizasse não só a região noroeste de Mato Grosso, mas também as áreas de cerrado de Rondônia, Acre e Amazonas. Para tanto, os dois empresários trouxeram técnicos americanos para os estudos preliminares da hidrovia. Mas havia um problema fundamental: não havia recursos financeiros suficientes para levar adiante o projeto. Blairo afirmava que não possuía uma produção de soja suficiente, e havia sempre a mesma dúvida: quem garantiria o que (sic)?

Durante o governo do presidente Fernando Collor de Mello (1990-92), o principal parceiro de Blairo, o empresário Hernandes, estava com sérias dificuldades financeiras e se afastou do projeto que, até então, era só uma idéia sem nada materializado. Com o recuo do Grupo Hernandes, o Grupo André Maggi passou a ter o controle societário da Hermasa.

O cenário só mudou em 1994, quando Blairo se encontrou com o então deputado estadual de Mato Grosso, Wilson Santos, que tinha um irmão deputado estadual no Amazonas, Wilton Campos. Blairo e Wilson decidiram apresentar o projeto da hidrovia ao Governador Amazonino Mendes, que já manifestara interesse em interiorizar a economia do estado através da agricultura. Depois da reunião com Amazonino, Blairo firmou uma parceria financeira para a instalação da hidrovia.

Nessa época, a região da Chapada dos Parecis, em Mato Grosso, possuía uma produção, rendimento médio e área plantada de soja já bastante expressiva (IBGE, 1996) estimulando a entrada do BNDES no projeto. Em escala nacional, de um lado, Mato Grosso já se afirmara com uma das principais áreas de produção de soja do país; de outro, o avanço da fronteira agrícola da soja se consolidara no Centro-Oeste brasileiro.

Do total dos investimentos na obra o Grupo André Maggi entrou com R \$ 28 milhões, o governo do Amazonas financiou R\$ 21 milhões e o BNDES R \$ 27 milhões. Desse modo, a parceria entre iniciativa privada e o poder público viabilizou a inauguração da hidrovia Madeira-Amazonas, em 12 de abril de 1997, com a presença do Presidente da República, Fernando Henrique Cardoso, que incluíra tal projeto no chamado Programa Brasil em Ação.

Em 1998, o Governo do Amazonas detinha 43\% das ações da Hermasa, o Grupo André Maggi 52\% e o restante, 5\%, com a Petrobrás Distribuidora. Em 2001, o governo amazonense vendeu sua participação acionária da Hermasa para Blairo Maggi, que passou a deter $95 \%$ das ações da empresa. Em face da expansão da comercialização da soja através do sistema de hidrovia, Blairo negociou com Amazonino Mendes a compra das ações. Sob os auspícios do ideário neoliberal, o governo do Amazonas alegou que era importante sua saída do controle acionário da Hermasa, pois o Estado não tinha vocação para administrar tal empreendimento (sic). Com a concretização do negócio, o Grupo André Maggi consolidou sua liderança no transportę de grãos de soja na Amazônia brasileira. 


\section{A dimensão geográfica da Hidrovia do Madeira}

$\mathrm{O}$ rio Madeira faz parte da bacia hidrográfica do rio Amazonas. A hidrovia do Madeira possui extensão de $1.015 \mathrm{Km}$ entre a cidade de Porto Velho (RO) e Itacoatiara, no rio Amazonas. Até a consolidação da hidrovia, a navegação era precária, visto que não havia manutenção regular de dragagens. $O$ regime das águas e o solapamento natural das margens comprometiam a pouca sinalização existente.

O rio Madeira é considerado um rio novo, sob o ponto de vista geológico, ou seja, seu leito ainda está em fase de definição. Desse modo, a cada ciclo hidrológico, o canal de navegação se altera. Além disso, outros fatores constituem problemas à navegação: os desbarrancamentos das margens, as atividades ilegais de garimpo, extração de seixo e lançamento de lixo nos barrancos. Assim sendo, a sinalização do rio é fundamental.

Implementar uma navegação 24 horas por dia, durante o ano todo, significou instalar uma rede de 12 estações fluviométricas para sondagens batimétricas em Itacoatiara, Uricurituba, Nova Olinda do Norte, Borba, Vista Alegre, Novo Aripuanã, Manicoré, Bom Intento, Vila Carará, Humaitá, Conceição da Galera e Porto Velho. O levantamento batimétrico da calha do rio permitiu maior definição das margens e contorno das ilhas, de modo a obter um controle da navegação (AHIMOC, 2000).

$\mathrm{Na}$ época da estiagem, quando o rio atinge o seu nível mínimo de profundidade, utiliza-se o balizamento flutuante, com várias placas de sinalização às margens do rio. A partir dos arquivos digitais das plantas batimétricas elabora-se uma carta eletrônica da hidrovia, utilizada com o Sistema de Posicionamento Global -GPS- e demais instrumentos, tais como radar, ecosonda, etc. Essa intensa tecnificação do espaço garante a navegação 24 horas por dia, sob quaisquer condições climáticas, visto que 0 sistema ainda apresenta estações liminimétricas dotadas de sensores digitais automáticos de níveis de chuva, com transmissão em tempo real para os centros de coleta de dados situados nos portos de origem e destino da hidrovia, a fim de estabelecer, no momento de embarque da carga, o calado máximo de segurança do comboio (AHIMOC, 2000).

Através da carta eletrônica viabiliza-se o monitoramento via satélite das embarcações, ao longo do rio. As barcaças enviam informações de sua posição via GPS para a empresa AUTOTRAC, localizada em Brasília, e os dados são acessados via modem nos escritórios da Hermasa em Itacoatiara e Porto Velho. Nos portos, todas as operações de carga e descarga são realizadas com equipamentos de alta tecnologia, tais como dutos impermeáveis que transferem grãos para dentro e para fora das barcaças.

\section{A logística espacial da Hidrovia Madeira}

Maior rio do mundo em volume de água, o Amazonas tem uma profundidade que 
permite a navegação de embarcações de grande porte a mais de mil quilômetros de sua foz. Com isso, as barcaças que saem de Porto Velho não precisam se dirigir até o Oceano Atlântico. Os navios procedentes da Europa e Ásia sobem o rio Amazonas até o terminal graneleiro de Itacoatiara, para onde chegam as barcaças provenientes de Porto Velho.

O projeto de transformar o rio Madeira numa hidrovia resultou num corredor de exportação de grãos e de importação de insumos agrícolas, transformando Itacoatiara em um centro de armazenamento e escoamento da produção de soja da Chapada dos Parecis, no Mato Grosso, Rondônia e municípios de Humaitá e Lábrea, no sul amazonense.

O corredor de exportação Sapezal/Madeira/Amazonas é formado pela produção de soja da Chapada dos Parecis, sul de Rondônia e Amazonas, em áreas de domínio prévio de cerrado. De Sapezal (MT) percorre-se 100 quilômetros de estrada de terra até Comodoro. Depois, percorrem-se mais 880 quilômetros de asfalto da rodovia BR364 até o terminal de Porto Velho, de onde barcaças com capacidade para 2.000 toneladas transportam a soja até o porto de Itacoatiara. Esse percurso é feito em dois dias e meio e o retorno leva o dobro do tempo por ser contra a correnteza (Hollanda, 1997). Em Itacoatiara, há um terminal de onde é embarcada a produção de soja do Estado de Roraima.

A produção agrícola da Chapada dos Parecis (MT) chega a Porto Velho pela rodovia BR-364, para ser descarregada nos silos graneleiros. Daí vai para as barcaças por modernos sistemas de correias alimentadoras. Após ser transportada ao longo do rio Madeira, depois de 1.015 quilômetros, a carga chega em Itacoatiara, onde é transferida para os silos ou diretamente para os navios oceânicos (Revista Granja, 1998). Até 1996, a safra para exportação da Chapada dos Parecis percorria mais de 2.500 quilômetros até os portos de Santos (SP) e Paranaguá (PR). O transporte da soja pelas águas do Madeira e Amazonas economiza cerca de 30\% do valor do frete, se comparado com o custo/Paranaguá. Maior rapidez no escoamento da soja através da hidrovia do Madeira transformou o porto de Itacoatiara no terceiro maior porto brasileiro em movimentação de soja, atrás apenas de Paranaguá e Santos, respectivamente.

A gestão territorial da hidrovia envolve um sistema de objetos e ações. Assim sendo, sua espacialidade encerra a presença de dois portos fluviais e terminais graneleiros (Porto Velho e Itacoatiara), escritórios centrais e filiais da Hermasa. A sede da empresa se localiza em Manaus e as filiais em Porto Velho e Itacoatiara. Além disso, armazéns de grande capacidade foram instalados nos terminais fluviais. As interações espaciais entre estas formas se dão através de rede de comunicações telemáticas. A tendência de superação do espaço pelo tempo não se dá somente através das distâncias absolutas entre as áreas de produção de soja e os portos do sul do país. O controle on-line da navegação por satélite garante a gestão territorial do fluxo de mercadoria. Computadores a bordo das barcaças permitem o monitoramento da rota dos barcos através de GPS e das informações repassadas pela empresa AUTOTRAC via modem para os escritórios da Hermasa nos portos fluviais. 


\section{O papel da hidrovia Madeira na competição intercapitalista global}

A malha programada de duplo controle, técnico e político, instituída pelo Grupo André Maggi, para consolidar sua posição de liderança na comercialização de grãos de soja, implica o avanço da fronteira agrícola capitalista, incorporando áreas do cerrado. Planejada estrategicamente para resolver dois dos principais problemas dos produtores da vasta e distante Chapada dos Parecis, o escoamento da safra e o insumo para a lavoura, a hidrovia expressa o domínio do grande capital privado no circuito mercantilfinanceiro da soja brasileira. Ao adquirir o controle acionário da Hermasa, Blairo Maggi não só afastou a presença do Estado, já que os recursos públicos não eram mais importantes, mas adquiriu capacidade de competir com grupos transnacionais que lideravam a comercialização da soja para mercados externos.

O Porto de Itacoatiara transformou o Grupo André Maggi numa trading, uma empresa voltada para a logística de comercialização de grãos de soja. Da produção de Mato Grosso, a Empresa Sementes Maggi comercializa entre 17 a $20 \%$ e da produção nacional, em torno de 6\%, conforme informações de Blairo Maggi (Entrevista 11/06/01).

Apesar de ser um grande produtor de soja, Blairo Maggi está mais preocupado em participar do circuito espacial mercantil-financeiro da soja em escala internacional. Para tanto, a competição com os grupos multinacionais se estabelece. Um dos diferenciais do Grupo André Maggi na concorrência intercapitalista é sua presença junto ao produtor. A rede de financiamento da produção, que envolve bancos externos (tradings transnacionais), a Empresa Sementes Maggi, o produtor e a indústria de insumos agrícolas, captura o agricultor para a esfera de influência do Grupo André Maggi. Blairo resume tais articulações da seguinte forma:

Hoje em dia me financio no exterior e financio o produtor para que ele produza a soja, com taxas de juros mais interessantes e com prazos maiores que condizem com a realidade dele. Então o produtor toma dinheiro emprestado da Sementes Maggi, que pediu empréstimo no exterior, o produtor produz a soja e entrega para mim. Eu liquido a operação financeira dele, exporto o grão e pago o banco lá fora. Então essa proximidade com o produtor nos deu uma grande vantagem frente aos nossos competidores.

Apesar de todo esse esforço, o Grupo André Maggi sofre intensa pressão das tradings internacionais, que tentam ter o controle dos elementos-chave da comercialização de grãos de soja no Brasil.

A presença do Grupo, ao longo do ano, junto ao produtor, dando-lhe recursos financeiros e assistência técnica, é o tipo de estratégia que as multinacionais ainda não realizam. Após a comercialização da produção, elas se afastam do produtor. A imagem de uma empresa que está sempre ao lado do produtor gera um atrativo a mais 
para a expansão da área de influência do grupo sobre a produção regional das antigas áreas de cerrado mato-grossense e rondoniense. Na relação de subordinação do produtor com o grupo, projeta-se o imaginário de uma confiança mútua, que Blairo sintetiza em poucas palavras:

É uma relação de confiança. Eu preciso do produtor para viabilizar o porto e o produtor precisa de mim. Nenhum dos dois pode falhar. Esse negócio tem muito de tradição. Uma vez cliente sempre cliente mesmo, você não pode falhar com ele.

Apesar de já ter um forte domínio no sudeste mato-grossense, a pressão das maiores multinacionais do país no comércio de grãos de soja, tais como CARGILL e CEVAL, se intensificou sobre o Grupo André Maggi a partir de 1994. As empresas tentaram incorporar as atividades de financiamento do grupo junto ao produtor.

Nessa época, algumas empresas começaram a serem incorporadas. A CARGILL comprou o Grupo Maragantu do Paraguai (processamento de soja) e a MATOSUL (processamento de soja), em 1996. Antes, a CEVAL (hoje Bunge Y Born) havia incorporado a TEKA, empresa voltada para a industrialização da soja, sediada em Cuiabá. A ADM americana incorporou a SADIA em Rondonópolis, em 1998.

Em linhas gerais, o circuito mercantil-financeiro da soja era formado por cerealistas e dezenas de esmagadoras de soja. As opções de venda do produto eram enormes. Havia uma certa disputa pela mercadoria, ao longo do ano, porque havia várias empresas comprando de vários cerealistas. Assim sendo, as multinacionais transformaram essa lógica do mercado da soja. Ao invés de várias esmagadoras, as incorporações realizadas reduziram-nas para poucas unidades, formando um oligopólio no setor de processamento da soja. Desse modo, grupos como a CARGILL e CEVAL passaram a implantar uma estratégia de ir até o campo para adquirir a produção local, deslocando o papel dos cerealistas, que acabaram sendo incorporados e praticamente desapareceram.

Nesse momento, Blairo Maggi tomou a decisão mais importante para o destino do Grupo, diante desse processo agressivo de domínio das multinacionais na comercialização de grãos. A estratégia de instalar o corredor multimodal de exportação no rio Madeira foi fundamental. Mesmo porque não havia muita alternativa.

As esmagadoras de soja também vendiam a produção para clientes no mercado externo. A empresa Matosul, por exemplo, mantinha interações comerciais com uma trading suíça. Quando a CARGILL incorporou a Matosul, esse grupo ficou sem mercadoria e não tinha interesse em ficar subordinado a uma empresa multinacional, como a CARGILL. Durante esse impasse, Blairo Maggi se lançou, de forma mais intensa, à conquista do mercado internacional. Desse modo, ele buscou se articular com aquelas tradings que perderam empresas brasileiras estratégicas na comercialização de soja. Assim sendo, Blairo passou a atender um mercado que as multinacionais, aqui presentes, não atendiam, apesar das incorporações. Sem a hidrovia Madeira-Amazonas essa prática socioespacial seria inviável.

A partir da inauguração do corredor de exportação no rio Madeira, Blairo Maggi 
começou a se inserir, cada vez mais, no circuito global de comercialização da soja brasileira, definindo uma posição de destaque frente as multinacionais, como CARGILL, BUNGE Y BORN e ADM.

A estratégia de Blairo Maggi foi audaciosa. Ele afirmou que:

No momento em que as multinacionais nos colocaram no canto para nos comprar, elas deixaram a guarda aberta lá fora e nós fomos ter contato com esse pessoal. Desse modo, a grande virada da logística de comercialização da soja do Grupo André Maggi foi sair do foco nacional, de ser alimentado por bancos nacionais e por essas multinacionais, que davam suporte financeiro para nós, e fazer negócio lá fora com outras empresas e com bancos internacionais. E ai foi o grande pulo que a gente deu. E a partir desse momento, eles pararam de querer nos comprar porque nós já estávamos do tamanho deles aqui internamente.

Cabe ressaltar que essa decisão estava articulada à presença da hidrovia Madeira e ao aumento da produção de soja, na Chapada dos Parecis. Em síntese, o porto de Itacoatiara viabilizou o Grupo André Maggi como uma trading. De acordo com Blairo, "sem o porto não haveria nada disso. Eu tinha virado somente um produtor de grãos na parte da agropecuária. Teria vendido, saído ou quebrado o Grupo. Não havia como ficar no negócio diante do domínio das multinacionais".

Os primeiros contatos com as tradings internacionais já eram mantidos através do porto de Paranaguá, onde o grupo comercializava uma pequena parte de sua produção de soja com os mercados externos. O controle do corredor multimodal rodovia BR364-hidrovia Madeira-Amazonas e a expansão da produção na Chapada dos Parecis atraíram a atenção das tradings que estavam sendo deslocadas pelas multinacionais do país. Conforme Blairo:

Quando você sai no mercado com um novo corredor de exportação na Amazônia, quem ficou sozinho lá fora veio me procurar. Veio de imediato. $O$ caso do Sumitomo é um deles. Foram conversações rápidas que houveram para ter esses casamentos.

Blairo afirma que não foi uma conjuntura de crise que provocou esse processo de incorporação de indústrias processadoras de soja e de cerealistas. Para ele, "foi um apetite grande dos compradores externos que queriam monopolizar o comércio da soja, como a ADM que comprou a SADIA. A SADIA era uma grande empresa no esmagamento de soja e foi incorporada".

A rede de fixos e fluxos de comercialização de soja via corredor multimodal rodovia BR-364-Hidrovia Madeira-Amazonas envolve relações de produtores com a Sementes Maggi, para fins de financiamento, aquisição de insumos e venda da produção. Por 
outro lado, a Sementes Maggi capta recursos através das tradings, como SUMITONO, Cereol, TOEFER, etc. para repassar aos produtores. Em troca, comercializa a produção da soja através do porto. De lá, a soja se dirige para diversos portos e mercados na Ásia e Europa.

A fim de garantir a fluidez do espaço de comercialização da soja, a Sementes Maggi contrata os navios ou eles são arrendados pelas tradings para o transporte da soja até os mercados mundiais. No entanto, Blairo Maggi já pensa em verticalizar, cada vez mais, esse fluxo de mercadoria. No seu espaço de projeção para o futuro, o Grupo André Maggi busca se tornar uma trading internacional.

Através de escritórios na Europa, Estados Unidos e Ásia o grupo comercializaria a soja e transportá-la-ia até o seu destino final. Para tanto, será necessário que a corporação se livre da dependência dos recursos externos para financiamento à lavoura e passe a arcar com os custos do transporte até os portos internacionais.

\section{Impactos regionais da hidrovia Madeira}

A consolidação da Hidrovia Madeira-Amazonas e o seu controle pela Hermasa têm sido acompanhado pela incorporação de milhões de hectares de cerrado para o cultivo de soja na Chapada dos Parecis em Mato Grosso e áreas de cerrado rondoniense. Com efeito, Sapezal, Campo Novo dos Parecis, Campo de Julio, Diamantin e Comodoro se consolidaram com grandes produtores de soja de Mato Grosso.

A Chapada dos Parecis, que inclui o sul de Rondônia e as regiões noroeste e norte de Mato Grosso, representa um dilema para a Amazônia. Nessa região de cerrado está se consolidando uma estrutura produtiva com produtividade recorde de soja.

A expansão da lavoura da soja nos cerrados rondonienses e de áreas pontuais do Amazonas e Roraima forma a fronteira agrícola noroeste do país; inserida no avanço de um ordenamento territorial do circuito espacial da soja, controlado por grandes grupos, tais como o Grupo André Maggi, CARGILL, Bunge e outros.

A expansão da soja no Amazonas tem sido uma das prioridades do projeto chamado Terceiro Ciclo da Amazônia, promovido pelo ex-governador Amazonino Mendes. A política territorial prevê uma fase de desenvolvimento que privilegia a agricultura. Para tanto, algumas áreas de campos abertos de Humaitá, ao longo da hidrovia do rio Madeira, têm sido incorporadas à agricultura mecanizada da soja, apesar dos problemas ambientais, tais como laterização dos solos, desmatamento, perda de biodiversidade e exclusão de territorialidades legítimas ali presentes.

Em Itacoatiara, a presença do porto graneleiro serviu de base para a instalação da primeira indústria de esmagamento de soja do Grupo André Maggi. Para tanto, um armazém com capacidade para 110 mil toneladas foi construído. Através da parceria, o governo do Estado do Amazonas financiou $40 \%$ do projeto da fábrica de beneficiamento de óleo e de farelo de soja. Apesar de ainda não serem relevantes, os estudos para expansão da lavoura da soja no município estão em curso, através de 
cooperativas e apoio da Fundação Mato Grosso e da HERMASA.

Ainda do ponto de vista dos impactos, a instalação do porto em Itacoatiara tem impulsionado a economia do município. De um domínio da indústria madeireira, Itacoatiara possui hoje uma dinâmica sócio-produtiva em torno do porto da Hermasa, empresa que se tornou a maior empregadora local.

Em Roraima, o Grupo André Maggi ainda não consolidou sua área de influência. Mas já há planos de estender seus cultivos de soja para os cerrados do Estado, na calha norte do rio Amazonas. A Hermasa inclui, em seus projetos futuros, a navegabilidade do rio Branco, afluente do rio Negro, para transporte de grãos até o porto de Itacoatiara.

As condições climáticas funcionam como um dos atrativos à expansão da soja. Por estar localizado, predominantemente, no Hemisfério Sul, as chuvas se concentram entre abril e outubro, época de estiagem nos cerrados do sul da Amazônia. Desse modo, a dinâmica de comercialização se torna favorável. A COOPERNORTECooperativa dos Produtores de Soja de Roraima e a Frente Integrada de Desenvolvimento Rural de Roraima têm desenvolvido parcerias com produtores e o poder público, a fim de viabilizar a atração de agricultores. Para tanto, além das vantagens locacionais edafoclimáticas, o preço da terra é baixo (R\$ 10 a 100 por hectare), os incentivos fiscais e as facilidades de transporte via porto de Itacoatiara e rodovia BR-174 são fatores que poderão ampliar a área plantada e a produção de soja no Estado.

Em Rondônia, 50 mil toneladas de soja foram produzidas em 2001, sobretudo nos cerrados do sul do Estado. A safra de $98 / 99$ foi de 14,10 mil toneladas de grãos (CONAB, 2001). A expansão tem sido extremamente rápida. Em Porto Velho, a Hermasa instalou uma filial, através do porto graneleiro, garantindo a compra de toda a produção regional e a exportação pela hidrovia do Madeira.

Além da hidrovia, um dos fatores que justifica esse avanço da produção é a aquisição de insumos. Através do porto de Itacoatiara, o Grupo André Maggi importa fertilizantes, sobretudo de Israel, e repassa aos produtores de Mato Grosso, Rondônia e Amazonas. Até 1998, o adubo era trazido em carretas do sul do país, a cerca de 2,5 mil quilômetros de distância de Sapezal. Para a movimentação e estoque do produto, a Hermasa utilizou um armazém da Prefeitura de Itacoatiara para construir um porto somente para fertilizantes. De Itacoatiara o produto é transferido para as barcaças da Hermasa e transportado até Porto Velho. Daí o adubo é negociado com os produtores. De acordo com Blairo, "o fertilizante importado e transportado via hidrovia Madeira chega a Sapezal entre US\$ 30 e US\$ 40 mais barato que o adubo produzido no Rio de Janeiro e São Paulo". A redução do custo do frete e do insumo, bem como as pesquisas por novas variedades de sementes têm provocado uma expansão da área plantada e aumento da produtividade dos agricultores do cerrado vis-a-vis a do sul do país.

Simultaneamente, essa expansão aponta para uma aceleração do desmatamento na Amazônia. O plantio de soja se dá em detrimento das culturas da região. Se na 
década de 1980, a pecuária era a grande responsável pelo desmatamento, hoje em dia a devastação também se dá a partir da ação dos pequenos proprietários, que abrem caminho para as fazendas mecanizadas de soja.

Do ponto de vista ambiental, a expansão da soja têm sido realizada em áreas antes ocupadas por pastagens ou pela pequena produção de subsistência, em decorrência de alto custo do desmatamento de novas áreas. Cabe apenas lembrar que, o avanço da soja em áreas de cerrado não se dá apenas sobre áreas já ocupadas. Grandes extensões de terras "virgens" são apropriadas para o uso produtivo.

De acordo com ambientalistas, sem apoio do poder público, alguns pequenos agricultores são deslocados para áreas de florestas virgens, abrindo caminho para a lavoura da soja e expondo os ecossistemas locais à destruição através da contaminação dos rios, igarapés e lagos pelos insumos químicos, inviabilizando, portanto, as culturais das várzeas promovidas pelas populações ribeirinhas, conforme assinala Carvalho (1999).

Para os produtores de Sapezal, uma cidade com 8.000 habitantes, no noroeste do Mato Grosso, essa crítica dos ambientalistas soa como um obstáculo ao processo de desenvolvimento da agricultura brasileira. De acordo com Blairo Maggi, "existe a Amazônia de floresta e a do cerrado, onde se pode e se deve produzir".

De fato, não há dúvida que a floresta Amazônia está sujeita aos impactos do avanço da fronteira agrícola da soja. Nesse sentido, o Grupo André Maggi e demais corporações do agribusiness são os principais alvos dos movimentos ambientalistas.

Como não poderia ser diferente, os conflitos de territorialidade emergem e a resistência de vários grupos sociais se organiza através de ONG's internacionais, sindicatos, cooperativas etc. De um lado, tais grupos reivindicam experiências de cultivo florestal sustentável de produtos da própria flora regional. Por outro lado, o poder público, a Embrapa e os empresários defendem a consolidação da fronteira. Luiz Pagot, ex-superintendente da Hermasa e atual Secretário Estadual de Transporte de Mato Grosso, ratifica os interesses da corporação ao afirmar que: "nos últimos 5 anos temos desenvolvido pesquisas e exaustivamente mostrado aos agricultores o caminho para a fronteira agrícola noroeste". Para ele, não há risco ambiental, pois a lavoura será implantada em áreas já desmatadas. Concluindo, ressalta que "Rondônia tem 10 milhões de hectares disponíveis para agricultura e somente 1 milhão estão ocupados com lavouras diversas. Vamos plantar nas áreas destinadas à agricultura, seguindo o zoneamento econômico-ecológico do Estado" (in ÁVILA, 2001).

De acordo com Blairo Maggi, "existe a intenção clara de cercear as atividades econômicas e a geração de empregos, bem como o próprio desenvolvimento do país, por trás de algumas ONG's" (Jornal A Gazeta-MT, 11/06/99). Para ele, as preocupações ambientais escondem os interesses de grupos multinacionais em conter a expansão da produção agrícola brasileira. Desse modo, ratifica seu projeto de incorporação de novas áreas do cerrado, sobretudo em Mato Grosso.

Apesar do avanço da soja na Amazônia e dos problemas socioambientais decorrentes 
da lavoura mecanizada, o cerrado mato-grossense é a fronteira mais dinâmica para as forças capitalistas. Ainda não há tecnologia capaz de garantir uma produção de grande escala em áreas como Humaitá, onde os solos rasos e encharcados demandam investimento. De acordo com Blairo Maggi, é necessário consolidar a fronteira de Mato Grosso com a tecnologia já disponível. Antes disso, não existirá um grande estímulo para o deslocamento da lavoura da soja em direção ao Acre, Amazonas e Roraima. As experiências e a presença de agricultores, cooperativas e empresários funcionam como uma prática de antecipação espacial, visto que a tendência do movimento da fronteira é se expandir para novas áreas de campos abertos mais ao norte da Amazônia.

Se levarmos em conta a incorporação de novas áreas de produção de grãos no Pará, Amazonas, Acre e Roraima, a estratégia do Grupo André Maggi de garantir posição de destaque na comercialização de grãos envolve novos eixos de transporte, o que pode tornar mais complexa a logística espacial da corporação na Amazônia brasileira.

\section{Para não concluir}

O ordenamento territorial produzido pelo Grupo André Maggi em áreas de fronteira implica uma flexibilização rápida e constante dos objetos e ações que caracterizam sua organização espacial. Nesse sentido, a rede de fixos e fluxos que envolve a logística de transporte é parte integrante do atual período técnico científico-informacional da sociedade capitalista. A busca por maior velocidade nas transações mercantis incorpora uma densidade técnica expressa na abertura de novos eixos de transporte, tal como a hidrovia Madeira.

À medida que a produção da soja avança na Amazônia, o Grupo atua no sentido de redefinir os fluxos de mercadorias, investindo na melhoria de rodovias, conclusão de ferrovias e implantação de hidrovias. Por outro lado, a construção de uma rede de fluxos, patrocinada pela iniciativa privada e pelo Estado, redireciona o movimento da fronteira agrícola capitalista. A expansão da soja em Rondônia e Amazonas é um exemplo ilustrativo.

As práticas espaciais de Blairo Maggi estão voltadas para garantir posição de destaque no agronegócio da soja, que é a principal preocupação do grupo. É a partir deste ponto que a corporação define e redefine seu ordenamento territorial em rede. São as interações espaciais impostas pelas determinações externas de preços da soja no mercado internacional e a acessibilidade aos portos do sul do país e daí ao mercado internacional que influenciam as decisões sobre logística de transporte e expansão da produção de soja em direção à Amazônia.

Cabe lembrar que o ordenamento territorial em rede do Grupo André Maggi não se define apenas pelas atividades econômicas, mas, antes de tudo, pela rede política que Blairo Maggi articula como condição para a reprodução ampliada do capital. Daí as 
articulações estratégicas com tradings, poder público, partidos políticos e produtores. As interações espaciais em rede são, na verdade, expressão das práticas políticas e do conteúdo ideológico do processo de modernização da agricultura brasileira em áreas de cerrado. Qualquer mudança nos objetivos estratégicos do grupo implica redefinição da rede política e da articulação com o espaço.

No entanto, política é também articulação da divergência social. E o espaço geográfico é reflexo e condição dessas contradições sociais. Logo, o projeto de implantação de novos corredores de exportação da produção de grãos traduz a lógica do capital e provoca imensos conflitos sociais no âmbito dos problemas socioambientais. A rede de fluxos de transporte multimodal que o Grupo projeta para a Amazônia é depositária de uma forma-conteúdo que representa os interesses de uma totalidade social capitalista homogeneizadora, que resulta na oposição de grupos sociais que se sentem marginalizados, bem como no debate em torno da destruição da biodiversidade do cerrado e campos da Amazônia.

Se pensarmos no projeto da hidrovia do Madeira, percebe-se que Blairo Maggi focaliza sua logística em projetos capazes de definir interações mercantis-produtivasfinanceiras regionais e internacionais. Selecionar e se antecipar a futuros focos dinâmicos, pressionando a ação do Estado, é uma das prioridades da corporação. Assim sendo, ao mesmo tempo em que pesquisas de variedade de soja são feitas em locais selecionados como Santarém, Humaitá, Boa Vista e Macapá, entre outros, o discurso e as articulações políticas de Blairo Maggi se direcionam para os projetos de hidrovias e pavimentação da BR-163. Analisando o potencial de abertura de mais de 5 milhões de hectares de terras para a agricultura em Mato Grosso, somente com a consolidação do eixo rodoviário da BR-163, Blairo tem investido nas regiões de Lucas do Rio Verde, Sorriso e Sinop, municípios mato-grossenses.

De fato, sua defesa da implantação das hidrovias revela a lógica empresarial que lhe é peculiar. Os maiores obstáculos materiais são os conflitos de territorialidade e de defesa do meio-ambiente. Infelizmente, a logística que envolveu o seu projeto de expansão da sua área de influência na Amazônia através da hidrovia do Madeira não foi acompanhado por fortes movimentos ambientalistas, tal como no caso da Hidrovia Araguaia-Tocantins. A antecipação espacial foi um fator determinante. Com efeito, Blairo impôs a construção de um espaço de circulação de mercadorias cuja (geo)grafia se projeta sobre o curso do rio Madeira, ou seja, sobre um espaço concreto socialmente construído por diversos grupos sociais, cujos problemas sociais demandam investigação da academia.

\section{A LOGÍSTICA DA HIDROVIA DO MADEIRA NA EXPANSÃO DA SOJA NA AMAZÔNIA}

Resumo: Este artigo objetivo analisar a gênese e impactos da hidrovia do Madeira sob a égide do Grupo André Maggi, uma das maiores corporações do agronegócio no Brasil. Em linhas gerais, a hidrovia possibilitou a subordinação da renda do produtor, 
expansão da lavoura de soja em direção à Amazônia, impactos socioambientais e corporatização de parcelas da Chapada dos Parecis sob a ação do Grupo André Maggi através do financiamento e comercialização da produção de grãos.

Palavras-chaves: hidrovia Madeira, corporação, Amazônia.

\section{LOGISTICS OF MADEIRA WATERWAY IN THE SOYABEAN EXPANSION IN AMAZON REGION}

Abstract: This article aims to analyze the impacts of the Madeira waterway, controlled by Andre Maggi Group, one of the largest agribusiness corporation in Brazil. In general, the waterway made possible the subordination of the producer's income, the expansion of soybean crops towards the Amazonia, social impacts and land control in part of the Chapada of the Parecis under the action of the Andre Maggi Group through the financing and commercialization of the grain production.

Keywords: Madeira Waterway, corporation, Amazon Region.

\section{BIBLIOGRAFIA}

AHIMOC. 2001. Administração das Hidrovias Ocidental. Ministério dos Transportes. http://www.transportes.gov.br

AVILA, Cristina. 2001. A soja rumo ao Norte. Revista Correio, 27/02/2001.

BECKER, Bertha. 1988. Elementos para construção de um conceito sobre gestão do território. Texto LAGET, $\mathrm{N}^{\circ} 1$ (1-5). Rio de Janeiro:UFRJ.

CARVALHO, Renata. 1999. A Amazônia rumo ao ciclo da soja. Amigos da Terra: Programa Amazônia, setembro.

HOLLANDA, Eduardo. 1997.Caminho das Águas. Revista Isto É, 23 de abril. IBGE. 1996.CENSO AGROPECUÁRIO DE MATO GROSSO.

REVISTA GRANJA.1998. Ele viabilizou o desenvolvimento do Brasil Central. Janeiro/98.

SANTOS, Milton. 1996. A Natureza do espaço: técnica e tempo. Razão e emoção. São Paulo:Hucitec. 